\title{
Postoperative re-irradiation using stereotactic body radiotherapy for metastatic epidural spinal cord compression
}

\author{
Kei Ito, MD,,3 Keiji Nihei, MD, PhD, ${ }^{1}$ Takuya Shimizuguchi, MD, ${ }^{1}$ Hiroaki Ogawa, MD, ${ }^{1}$ \\ Tomohisa Furuya, PhD, ${ }^{1}$ Shurei Sugita, MD, PhD, ${ }^{2}$ Takahiro Hozumi, MD, PhD, ${ }^{2}$ \\ Keisuke Sasai, MD, PhD, ${ }^{3}$ and Katsuyuki Karasawa, MD, PhD'

\begin{abstract}
1Division of Radiation Oncology, Department of Radiology, and 2Department of Orthopedics, Tokyo Metropolitan Cancer and Infectious Diseases Center Komagome Hospital; and '3epartment of Radiology, Graduate School of Medicine, Juntendo
\end{abstract} \\ University, Tokyo, Japan
}

\begin{abstract}
OBJECTIVE This study aimed to clarify the outcomes of postoperative re-irradiation using stereotactic body radiotherapy (SBRT) for metastatic epidural spinal cord compression (MESCC) in the authors' institution and to identify factors correlated with local control.
\end{abstract}

METHODS Cases in which patients with previously irradiated MESCC underwent decompression surgery followed by spine SBRT as re-irradiation between April 2013 and May 2017 were retrospectively reviewed. The surgical procedures were mainly performed by the posterior approach and included decompression and fixation. The prescribed dose for spine SBRT was $24 \mathrm{~Gy}$ in 2 fractions. The primary outcome was local control, which was defined as elimination, shrinkage, or no change of the tumor on CT or MRI obtained approximately every 3 months after SBRT. In addition, various patient-, treatment-, and tumor-specific factors were evaluated to determine their predictive value for local control.

RESULTS Twenty-eight cases were identified in the authors' institutional databases as meeting the inclusion criteria. The histology of the primary disease was thyroid cancer in 7 cases, lung cancer in 6 , renal cancer in 3 , colorectal cancer in 3 , and other cancers in 9 . The most common previous radiation dose was $30 \mathrm{~Gy}$ in 10 fractions (15 cases). The mean interval since the most recent irradiation was 16 months (range 5-132 months). The median duration of follow-up after SBRT was 13 months (range 4-38 months). The 1-year local control rate was $70 \%$. In the analysis of factors related to local control, Bilsky grade, number of vertebral levels in the treatment target, the interval between the latest radiotherapy and SBRT, recursive partitioning analysis (RPA), the prognostic index for spinal metastases (PRISM), and the revised Tokuhashi score were not significantly correlated with local control. The favorable group classified by the Rades prognostic score achieved a significantly higher 1-year local control rate than the unfavorable group (1-year local control rate: $100 \%$ vs $33 \% ; p<0.01$ ). Radiation-induced myelopathy and vertebral compression fracture were observed in 1 and 3 patients, respectively. No other grade 3 or greater toxicities were encountered.

CONCLUSIONS The results indicate that spine SBRT as postoperative re-irradiation was effective, and it was especially useful for patients classified as having a good survival prognosis according to the Rades score.

https://thejns.org/doi/abs/10.3171/2018.1.SPINE171155

KEYWORDS postoperative spine SBRT; MESCC; re-irradiation; decompressive surgery; oncology

$\mathrm{S}$ PINAL metastases are diagnosed in approximately $40 \%$ of cancer patients, ${ }^{10}$ and metastatic epidural spinal cord compression (MESCC) occurs in up to $10 \%$ of adult cancer patients during their disease course. ${ }^{17,18}$ MESCC is one of the most dreaded complications of met- astatic cancer, because it usually causes progressive pain, paralysis, sensory loss, and sphincter dysfunction.

A randomized, controlled trial demonstrated that, for patients with symptomatic single-level MESCC, surgical decompression followed by conventional radiation thera-

ABBREVIATIONS CTV = clinical target volume; IMRT = intensity-modulated radiation therapy; IORT = intraoperative radiotherapy; MESCC = metastatic epidural spinal cord compression; OAR = organ at risk; PRISM = prognostic index for spinal metastases; PTV = planning target volume; RPA = recursive partitioning analysis; RT = radiation therapy; SBRT = stereotactic body radiotherapy.

SUBMITTED October 20, 2017. ACCEPTED January 31, 2018.

INCLUDE WHEN CITING Published online June 15, 2018; DOI: 10.3171/2018.1.SPINE171155. 
py (RT) of 30 Gy in 10 fractions is the first-line therapy ${ }^{16}$ However, the standard treatment has 2 limitations. First, in patients with a history of irradiation, the standard RT dose of $30 \mathrm{~Gy}$ in 10 fractions cannot be applied; $30 \mathrm{~Gy}$ in 10 fractions as second-course RT has not been proven safe in prospective clinical trials. ${ }^{4}$ Second, the long-term local control rate is low. One study reported that local progression, evaluated by radiographic findings, occurred in as many as $70 \%$ of patients at 1 year after conventional postoperative RT. ${ }^{9}$ With innovations in systemic therapy dramatically extending life expectancy for patients with metastatic disease, the need for safe re-irradiation and long-term local control of spinal metastases is growing.

Stereotactic body radiotherapy (SBRT) with intensitymodulated radiation therapy (IMRT) and an image guidance technique has emerged as a new treatment option for spinal metastases ${ }^{13}$ and has been applied to patients following surgery. ${ }^{27}$ SBRT can spare the adjacent organs at risk (OARs), while delivering high-dose radiation to the target volume. Spine SBRT, therefore, could provide safe re-irradiation and a high local control rate. The purpose of this study was to clarify the outcomes of postoperative reirradiation using SBRT for MESCC in our institution and to identify factors correlated with local control.

\section{Methods}

\section{Patients and Data Acquisition}

A retrospective review of the databases of Tokyo Metropolitan Cancer and Infectious Diseases Center Komagome Hospital (Tokyo, Japan) was performed to identify patients treated with spine SBRT from April 2013 to May 2017. Patients were included if they met the following criteria: 1) MESCC diagnosed by CT or MRI; 2) the spine lesion was previously irradiated with a dose of $30 \mathrm{~Gy}$ in 10 fractions or a higher dose; 3 ) the spine lesion was treated with decompression surgery prior to SBRT; and 4) the spine lesion was treated with re-irradiation SBRT. We have conducted SBRT with an interval longer than 5 months from the latest irradiation based on the report by Sahgal et al. ${ }^{23}$ Patients who had previously undergone spine SBRT to the same spinal level were excluded.

\section{Embolization and Surgical Procedure}

Before the surgical procedure, each patient underwent preoperative angiography and embolization of segmental arteries. Selective catheterization of the corresponding and consecutive levels of segmental arteries was performed to control intraoperative bleeding.

Surgical procedures were mainly performed by the posterior approach, with decompression and fixation. Decompression of the spinal cord was accomplished by laminectomy at the level of the tumor site and curettage of the surrounding tumor. The goal of curettage was to create at least a 3-mm tumor-free space around the spinal cord. Posterior fixation was accomplished using pedicle screws, rods, and hooks. The extent of fixation was usually 2 levels above and 2 levels below the affected vertebrae (Fig. 1).

\section{Stereotactic Body Radiotherapy}

Patients were immobilized using a full-body evacuated cushion (CIVCO Medical Solutions) in a stable supine position. Planning CT simulation was performed with a slice thickness of $1 \mathrm{~mm}$, and all patients underwent MRI for delineation of the tumor and the spinal canal. The clinical target volume (CTV) included the residual disease, the entire preoperative extent of bony epidural disease, spinal instrumentation, and the surgical incision, plus immediately adjacent bony anatomical compartments at risk of microscopic disease extension as described by contouring guidelines for postoperative spine SBRT. ${ }^{21}$ (Surgical instrumentation and the incision used to be included in the CTV but no longer are.) The spinal cord and cauda equina were contoured with T2-weighted MRI. Other OARs were contoured based on simulation CT images. A 2-mm margin was added to the CTV to create the planning target volume (PTV), and a $1.5-\mathrm{mm}$ margin was added to the spinal cord to create the spinal cord planning OAR volume (PRV). For the cauda equina, the thecal sac was contoured with no additional margin. The prescribed dose was $24 \mathrm{~Gy}$ in 2 fractions. Under the condition that the minimum dose to $95 \%$ of the PTV was greater than $70 \%$ of the prescribed dose, the delivered dose was set as high as possible to satisfy the constraints for the adjacent organs. Taking into consideration previously delivered radiation doses, dose constraints were set for the spinal cord and the cauda equina so that the maximum point dose (with point defined as $0.035 \mathrm{cc}$ or less ${ }^{1}$ ) was less than 11.0-12.2 Gy, based on the report by Sahgal et al. (Fig. 1). ${ }^{23}$ All patients received SBRT using a Vero 4-Dimensional Radiation Therapy (Vero4DRT) unit (Mitsubishi Heavy Industries, Ltd., and BrainLab AG) equipped with a 5-mm multileaf collimator, kilovoltage cone beam CT image guidance system and 6 degrees of freedom patient position corrections.

\section{Evaluation}

The endpoints of the present study were overall survival, local control, ambulatory function, and adverse events. Local control was defined as elimination, shrinkage, or no change of the tumor according to CT or MRI obtained approximately every 3 months after the SBRT. Some factors were selected as potential predictors, and their impacts on local control were assessed with a univariate model. These factors included the degree of compression classified by the Bilsky grade, ${ }^{14}$ the number of vertebral levels in the treatment target, the interval from the most recent previous irradiation to SBRT, and some prognostic scores. Recursive partitioning analysis (RPA), ${ }^{3}$ the prognostic index for spinal metastases (PRISM), ${ }^{28}$ the revised Tokuhashi score, ${ }^{28}$ and the Rades score ${ }^{19}$ were used as prognostic indices. RPA is a prognostic index for patients undergoing spine SBRT for spinal metastases. PRISM was created based on 2 prospective trials investigating SBRT for spinal metastasis. The revised Tokuhashi score is the prognostic index for determining the treatment strategy for spinal metastases reported by Tokuhashi et al. The Rades score is a prognostic index for survival after conventional RT for MESCC reported by Rades et al. Ambulatory function was evaluated on a 4-level scale: normal, walking with 1 cane, walking with a walker frame, and walking not possible. Adverse events were evaluated according to the Com- 

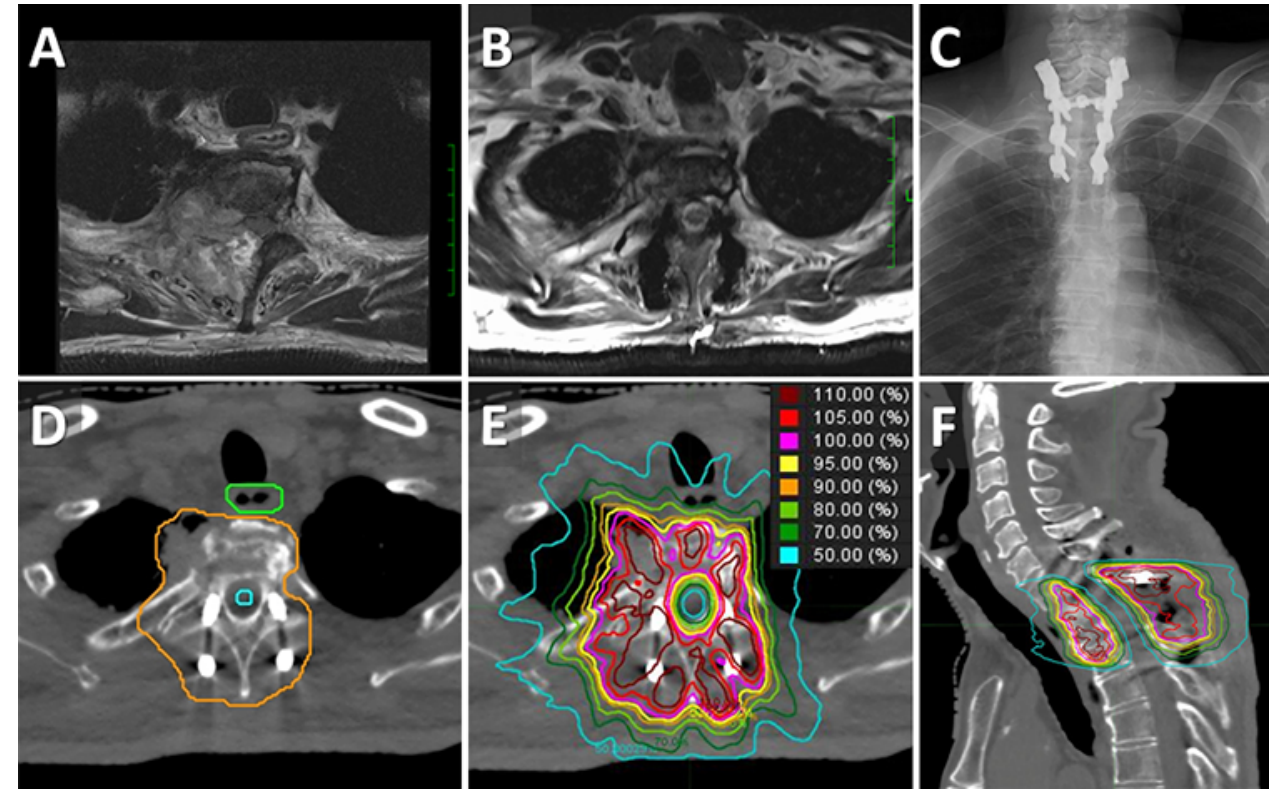

FIG. 1. Images obtained in a 60-year-old man with metastatic lung cancer lesions at T1 and T2. A: Preoperative axial T2-weighted MR image demonstrating Bilsky grade III MESCC. B: Postoperative axial T2-weighted MR image demonstrating Bilsky grade Ib disease. C: Postoperative anteroposterior radiograph. D: Axial CT image with contouring for planning SBRT. E and F: Axial (E) and sagittal (F) CT images showing dose distribution of SBRT. Figure is available in color online only.

mon Terminology Criteria for Adverse Events (CTCAE) version 4, from the US Department of Health and Human Services (National Institutes of Health and National Cancer Institute) ${ }^{6}$ and the Radiation Therapy Oncology Group (RTOG) and the European Organization for Research and Treatment of Cancer (EORTC) radiation morbidity scoring system. ${ }^{5}$

\section{Statistical Analysis}

Overall survival was defined as the time from the start date of SBRT until death from any cause. Local control was calculated in months from the start date of SBRT to the exacerbation date for the treated vertebral segment or the last follow-up imaging study if local control was maintained; death was not included as an endpoint for local control. The overall survival and local control rates were estimated using the Kaplan-Meier method, and log-rank tests were used to evaluate correlations between local control and potential predictors of interest. Results with $\mathrm{p}<$ 0.05 were considered statistically significant. All statistical analyses were performed with EZR (Saitama Medical Center, Jichi Medical University). ${ }^{8}$

\section{Results}

\section{Patient Characteristics}

A total of 28 patients (with 28 lesions) satisfied the eligibility criteria. Patient and tumor characteristics are summarized in Table 1 . One patient had a history of radiation with a carbon-ion beam. Eight patients received intraoperative radiotherapy (IORT). At the time that these patients underwent IORT, we routinely performed it with megavolt electron beam delivery using a conventional linear accelerator for MESCC at decompression surgery. Although a dose of 20 Gy was delivered with a posterior port, the radiation dose to the spinal cord was kept to less than 2 Gy by putting a lead plate on the spinal cord. ${ }^{11}$ However, concurrent therapy with IORT and SBRT was not conducted. Twelve patients underwent decompression surgery when they were previously treated with conventional RT, and 16 patients underwent surgery at the same point in their disease process at which they had SBRT. For these 16 patients, the median time from surgery to SBRT was 4 weeks (range 2-8 weeks).

\section{Clinical Outcomes}

The median duration of follow-up after spine SBRT was 13 months (range 4-38 months). Sixteen patients (57\%) died at a median of 11.5 months (range 4-38 months) from the time of spine SBRT, and all 16 patients died of systemic disease progression. The overall survival rate at 1 year was $63 \%$ (Fig. 2). The local control rate at 1 year was $70 \%$ (Fig. 3A). The best tumor responses were tumor shrinkage in 7 cases (25\%), stable disease in 16 cases (57\%), and tumor progression in 4 cases (14\%). Information on tumor response was not available in 1 case. Tumor elimination was not seen in any of the cases in this series. Seven patients had experienced local progression by the their last follow-up, and in the 5 of these patients for whom systemic imaging follow-up was available, exacerbation or emergence of metastatic lesions in other organs was confirmed at the time of occurrence of spine local failure. Table 2 shows the results of univariate analyses of factors predicting local treatment failure. Bilsky grade, the number of vertebral levels in the treatment target, interval from the latest RT to SBRT, the timing of decompression surgery at the last RT or SBRT, RPA, PRISM, and the revised Tokuhashi score were not significantly correlated with local 
TABLE 1. Summary of clinical and demographic characteristics of the 28 patients in this study

\begin{tabular}{|c|c|}
\hline Characteristic & Value \\
\hline \multicolumn{2}{|l|}{ Sex } \\
\hline Male & 18 \\
\hline Female & 10 \\
\hline \multicolumn{2}{|l|}{ Age in yrs } \\
\hline Median & 62 \\
\hline Range & $33-80$ \\
\hline \multicolumn{2}{|l|}{ ECOG PS } \\
\hline $0-1$ & 19 \\
\hline 2 & 7 \\
\hline 3 & 2 \\
\hline 4 & 0 \\
\hline \multicolumn{2}{|l|}{ Lesion histopathology } \\
\hline Thyroid & 7 \\
\hline Lung & 6 \\
\hline Renal cell & 3 \\
\hline Colorectal & 3 \\
\hline Other & 9 \\
\hline \multicolumn{2}{|l|}{ Levels treated ${ }^{*}$} \\
\hline Cervical & 6 \\
\hline Thoracic & 22 \\
\hline Lumbar & 4 \\
\hline \multicolumn{2}{|l|}{ Systemic disease } \\
\hline Controlled & 8 \\
\hline Active & 20 \\
\hline \multicolumn{2}{|l|}{ RT history† } \\
\hline $30 \mathrm{~Gy} / 10 \mathrm{fr}$ & 15 \\
\hline $20 \mathrm{~Gy} / 1 \mathrm{fr}$ (IORT) & 8 \\
\hline $40 \mathrm{~Gy} / 20 \mathrm{fr}$ & 3 \\
\hline $35 \mathrm{~Gy} / 14 \mathrm{fr}$ & 3 \\
\hline Other & 6 \\
\hline \multicolumn{2}{|c|}{ Interval btwn latest RT \& SBRT in mos } \\
\hline Median & 16 \\
\hline Range & $5-132$ \\
\hline \multicolumn{2}{|l|}{ Surgical decompression } \\
\hline At previous RT & 12 \\
\hline At SBRT & 16 \\
\hline \multicolumn{2}{|l|}{ Bilsky grade at SBRT } \\
\hline \multicolumn{2}{|l|}{0 or la (no compression) } \\
\hline 0 & 0 \\
\hline la & 0 \\
\hline \multicolumn{2}{|c|}{ Ib or lc (dural compression) } \\
\hline $\mathrm{lb}$ & 12 \\
\hline Ic & 3 \\
\hline \multicolumn{2}{|l|}{ II/III (cord compression) } \\
\hline II & 7 \\
\hline III & 6 \\
\hline
\end{tabular}

ECOG PS = Eastern Cooperative Oncology Group performance status; $\mathrm{fr}=$ fraction(s).

Values are numbers of patients unless otherwise indicated.

* Four patients had lesions that involved more than 1 spinal region.

† Seven patients had previously undergone 2 courses of RT.

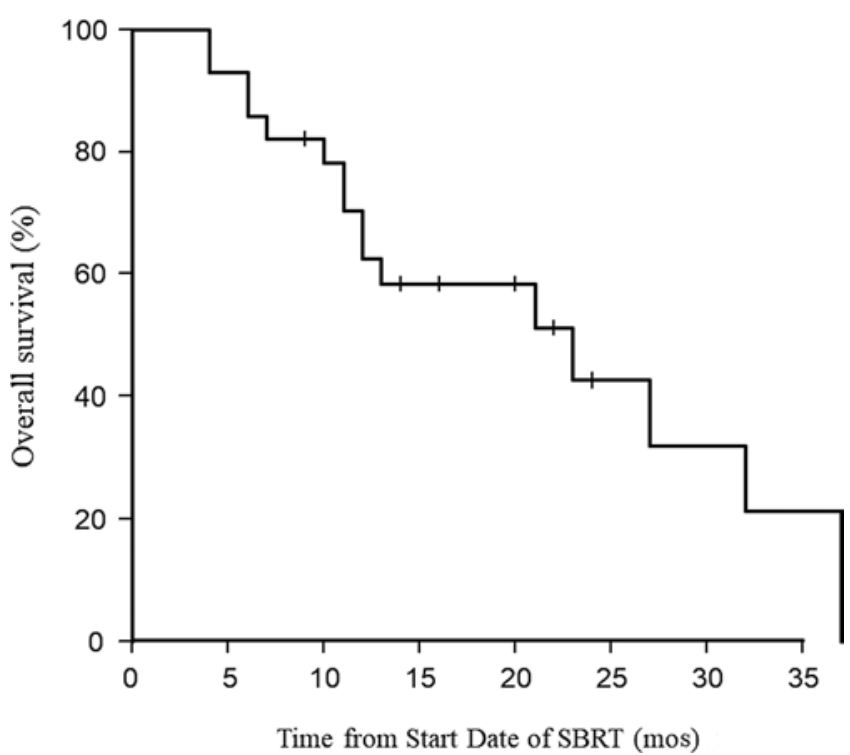

FIG. 2. Kaplan-Meier curve for overall survival after spine SBRT.

control. Classified by the Rades prognostic score, patients in the favorable group had significantly better local control than those in the unfavorable group (1-year local control rate: $100 \%$ vs $33 \%$; $<$ < 0.01) (Fig. 3B).

Figure 4 shows the number of patients with normal to difficult walking. Comparing ambulatory function between pretreatment and 1 year after SBRT, improvement was seen in 4 cases, no change in 11, and worsening in 5 .

Radiation-induced myelopathy and vertebral compression fractures were observed in 1 and 3 patients, respectively. No other grade 3 or greater toxicities were encountered. The patient with radiation-induced myelopathy had treatment to T10-12 metastases with a carbon-ion beam of $70.4 \mathrm{GyE}$, with GyE defined as the physical dose multiplied by the relative biological effectiveness of carbon ions, ${ }^{7}$ in 16 fractions. Seven years after carbon-ion RT, decompression surgery and SBRT were performed at the same spinal levels. Thirty months following SBRT, the patient developed complete paraplegia, with MRI showing no tumor progression.

\section{Discussion}

The outcomes of spine SBRT as postoperative re-irradiation for MESCC were investigated. Favorable survival prognosis based on the Rades score was significantly correlated with good local control.

First-line treatment for spinal cord compression caused by metastatic cancer is surgery followed by conventional radiotherapy of $30 \mathrm{~Gy}$ in 10 fractions. However, this treatment has 2 limitations: the safety of conventional reirradiation using $30 \mathrm{~Gy}$ in 10 fractions is unknown; and the long-term local control rate is low. Spine SBRT has the possibility to overcome these limitations of the standard treatment, since SBRT can create a steep dose gradient surrounding the spinal cord, while delivering ablative doses of radiation to the tumor. Some papers on postoperative SBRT have been published, and a systematic review 

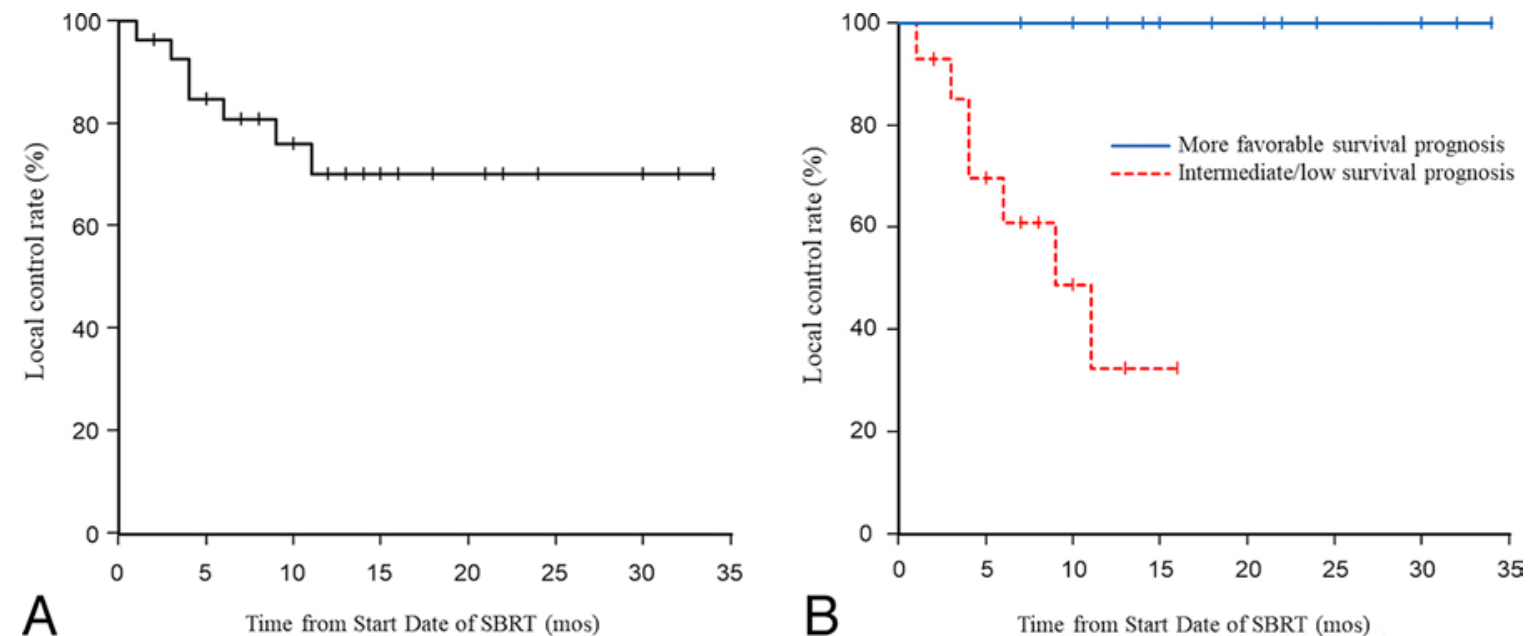

FIG. 3. Kaplan-Meier curve for local control after spine SBRT for the overall group (A) and stratified by Rades score (B). Figure is available in color online only.

article reported that the crude local control rate at the time of last follow-up was $88.6 \%$ in a sample of 426 patients..$^{20}$ This is similar what has been reported for re-irradiation SBRT without surgery. A systematic review article re-

TABLE 2. Univariate analysis for local control

\begin{tabular}{|c|c|c|c|}
\hline Variable & $\begin{array}{c}\text { No. of } \\
\text { Patients }\end{array}$ & $\begin{array}{c}\text { LC Rate* at } \\
1 \text { Year (\%) }\end{array}$ & $\begin{array}{c}p \\
\text { Value }\end{array}$ \\
\hline Bilsky grade & & & 0.09 \\
\hline lb or Ic (dural compression) & 15 & 86 & \\
\hline II or III (cord compression) & 13 & 49 & \\
\hline No. of levels & & & 0.32 \\
\hline 1 or 2 & 13 & 83 & \\
\hline 3 or more & 15 & 61 & \\
\hline Interval btwn latest RT \& SBRT & & & 0.80 \\
\hline$>12$ mos & 18 & 65 & \\
\hline$\leq 12 \mathrm{mos}$ & 10 & 79 & \\
\hline Surgical decompression & & & 0.66 \\
\hline At previous RT & 12 & 67 & \\
\hline At SBRT & 16 & 69 & \\
\hline RPA & & & 0.39 \\
\hline Group 1 & 15 & 78 & \\
\hline Groups 2 \& 3 & 13 & 61 & \\
\hline PRISM & & & 0.52 \\
\hline Groups $1 \& 2$ & 15 & 76 & \\
\hline Groups 3 \& 4 & 13 & 63 & \\
\hline Revised Tokuhashi score & & & 0.08 \\
\hline Intermediate/high & 18 & 79 & \\
\hline Low & 10 & 53 & \\
\hline Rades score & & & $<0.01$ \\
\hline More favorable survival prognosis & 13 & 100 & \\
\hline Intermediate/poor survival prognosis & 15 & 33 & \\
\hline
\end{tabular}

ported that spine SBRT as re-irradiation achieved a 1-year local control rate of $76 \% .{ }^{15}$ However, there have been no reports that were limited to patients with both elements of re-irradiation SBRT and SBRT after surgical decompression, although there are some reports that include such cases., ${ }^{2,12,27}$ The results of the present study suggest that postoperative spine SBRT for MESCC as re-irradiation was effective, with local control seen on imaging and a clinically acceptable safety profile.

All 5 patients with local failure who had adequate imaging studies for analysis showed exacerbations or emergence of other organ lesions at the time of local failure (adequate imaging studies were not available in the other 2 cases of local failure). The 1-year survival rate in the local failure group was significantly inferior to that in the locally controlled group $(43 \%$ vs $73 \%, p=0.02)$. In other words, the presence or absence of local failure might depend on

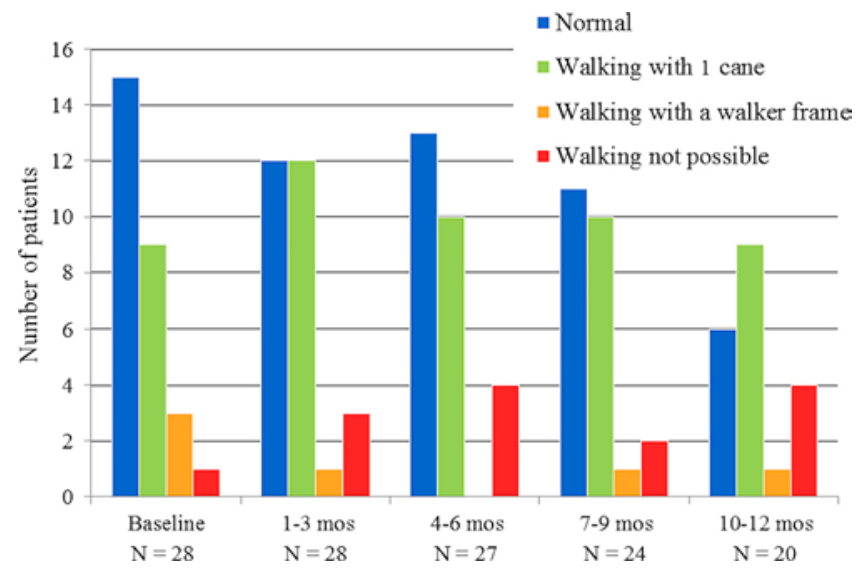

FIG. 4. Number of patients who could walk normally, with 1 cane, with a walker frame, or who had difficulty walking, before (baseline) and after SBRT (time measured from start of SBRT). Figure is available in color online only. 
the progress of systemic disease, and there could be a correlation between local control and the reported prognostic indices predicting the progress of systemic disease. In the present study, the correlations of 4 prognostic indices with local control were evaluated, and the Rades score showed significant correlations with local control.

One of the most important issues in the spine SBRT setting is the correct selection of patient candidates. Compared to conventional RT, spine SBRT requires greater planning time, additional personnel involvement, and considerable technical investment. Moreover, SBRT carries additional risks compared to conventional RT, including the potential for vertebral compression fractures, myelopathy, or radiculopathy. ${ }^{22,24,25}$ Therefore, it is necessary to identify which patients may benefit most from spine SBRT. The present study provides useful information for selecting eligible cases.

Among the 4 prognostic indices analyzed, the Rades score was found to be correlated with local control, and the revised Tokuhashi score also showed a strong trend toward correlation with local control. The difference between these 2 scores and the others might be due to factors that are only included in the Rades score and the revised Tokuhashi score-specifically, "type of primary tumor" and "ambulatory status before RT." However, the bias of the above factors was not identified from the individual data, and the definitive risk factor for local control could not be identified.

The limitation of the current study is that it focused primarily on local control among many endpoints. The primary endpoint should be quality of life or ambulatory function, since this treatment is classified as palliative therapy. However, the focus was primarily on local control, and univariate analysis was performed to identify factors related to local control. Quality of life was not selected as an endpoint because it was not measured in our daily clinical practice. Regarding ambulatory function, it was difficult to evaluate the efficacy of spine SBRT because difficulty walking due to worsening of the general condition or MESCC of other level spine lesions was included. As a result, local control was adopted as a surrogate primary endpoint for ambulatory function.

The patients included in the present study had the 2 elements of re-irradiation SBRT and surgical decompression followed by SBRT. Prospective clinical trials to prove the safety and efficacy of spine SBRT in each setting are required. Spine SBRT, exhibiting strong local control, should be used especially for patients with MESCC, and high-level evidence is needed for it to be widely adopted in practice. In addition, although re-irradiation SBRT is being widely adopted in practice with the dose constraints of the spinal cord reported from a retrospective study, ${ }^{23}$ it is also necessary to evaluate the outcomes by clinical trials. Based on the present results, we suggest that the Rades score should be included as an eligibility criterion in future clinical trials.

\section{Conclusions}

The 1-year local control rate of postoperative re-irradiation using SBRT for MESCC was 70\%. Postoperative re-irradiation SBRT appeared effective for patients with a good survival prognosis, and the Rades score seemed useful for patient selection.

\section{References}

1. Benedict SH, Yenice KM, Followill D, Galvin JM, Hinson W, Kavanagh B, et al: Stereotactic body radiation therapy: the report of AAPM Task Group 101. Med Phys 37:4078-4101, 2010 (Erratum in Med Phys 39:563, 2012)

2. Chan MW, Thibault I, Atenafu EG, Yu E, John Cho BC, Letourneau D, et al: Patterns of epidural progression following postoperative spine stereotactic body radiotherapy: implications for clinical target volume delineation. J Neurosurg Spine 24:652-659, 2016

3. Chao ST, Koyfman SA, Woody N, Angelov L, Soeder SL, Reddy CA, et al: Recursive partitioning analysis index is predictive for overall survival in patients undergoing spine stereotactic body radiation therapy for spinal metastases. Int J Radiat Oncol Biol Phys 82:1738-1743, 2012

4. Chow E, van der Linden YM, Roos D, Hartsell WF, Hoskin $\mathrm{P}, \mathrm{Wu}$ JS, et al: Single versus multiple fractions of repeat radiation for painful bone metastases: a randomised, controlled, non-inferiority trial. Lancet Oncol 15:164-171, 2014

5. Cox JD, Stetz J, Pajak TF: Toxicity criteria of the Radiation Therapy Oncology Group (RTOG) and the European Organization for Research and Treatment of Cancer (EORTC). Int J Radiat Oncol Biol Phys 31:1341-1346, 1995

6. Department of Health and Human Services: Common Terminology Criteria for Adverse Events (CTCAE) Version 4.0. (https://evs.nci.nih.gov/ftp1/CTCAE/CTCAE_4.03/ CTCAE_4.03_2010-06-14_QuickReference_5x7.pdf) [Accessed March 14, 2018]

7. Kanai T, Endo M, Minohara S, Miyahara N, Koyama-ito H, Tomura H, et al: Biophysical characteristics of HIMAC clinical irradiation system for heavy-ion radiation therapy. Int $\mathbf{J}$ Radiat Oncol Biol Phys 44:201-210, 1999

8. Kanda Y: Investigation of the freely available easy-to-use software 'EZR' for medical statistics. Bone Marrow Transplant 48:452-458, 2013

9. Klekamp J, Samii H: Surgical results for spinal metastases. Acta Neurochir (Wien) 140:957-967, 1998

10. Klimo P Jr, Thompson CJ, Kestle JR, Schmidt MH: A metaanalysis of surgery versus conventional radiotherapy for the treatment of metastatic spinal epidural disease. Neuro Oncol 7:64-76, 2005

11. Kondo T, Hozumi T, Goto T, Seichi A, Nakamura K: Intraoperative radiotherapy combined with posterior decompression and stabilization for non-ambulant paralytic patients due to spinal metastasis. Spine (Phila Pa 1976) 33:1898-1904, 2008

12. Laufer I, Iorgulescu JB, Chapman T, Lis E, Shi W, Zhang Z, et al: Local disease control for spinal metastases following "separation surgery" and adjuvant hypofractionated or highdose single-fraction stereotactic radiosurgery: outcome analysis in 186 patients. J Neurosurg Spine 18:207-214, 2013

13. Lutz S, Berk L, Chang E, Chow E, Hahn C, Hoskin P, et al: Palliative radiotherapy for bone metastases: an ASTRO evidence-based guideline. Int J Radiat Oncol Biol Phys 79:965-976, 2011

14. Moulding HD, Elder JB, Lis E, Lovelock DM, Zhang Z, Yamada Y, et al: Local disease control after decompressive surgery and adjuvant high-dose single-fraction radiosurgery for spine metastases. J Neurosurg Spine 13:87-93, 2010

15. Myrehaug S, Sahgal A, Hayashi M, Levivier M, Ma L, Martinez R, et al: Reirradiation spine stereotactic body radiation therapy for spinal metastases: systematic review. J Neurosurg Spine 27:428-435, 2017

16. Patchell RA, Tibbs PA, Regine WF, Payne R, Saris S, Kryscio RJ, et al: Direct decompressive surgical resection 
in the treatment of spinal cord compression caused by metastatic cancer: a randomised trial. Lancet 366:643-648, 2005

17. Prasad D, Schiff D: Malignant spinal-cord compression. Lancet Oncol 6:15-24, 2005

18. Rades D, Abrahm JL: The role of radiotherapy for metastatic epidural spinal cord compression. Nat Rev Clin Oncol 7:590-598, 2010

19. Rades D, Fehlauer F, Schulte R, Veninga T, Stalpers LJ, Basic $\mathrm{H}$, et al: Prognostic factors for local control and survival after radiotherapy of metastatic spinal cord compression. J Clin Oncol 24:3388-3393, 2006

20. Redmond KJ, Lo SS, Fisher C, Sahgal A: Postoperative stereotactic body radiation therapy (SBRT) for spine metastases: a critical review to guide practice. Int J Radiat Oncol Biol Phys 95:1414-1428, 2016

21. Redmond KJ, Robertson S, Lo SS, Soltys SG, Ryu S, McNutt $\mathrm{T}$, et al: Consensus contouring guidelines for postoperative stereotactic body radiation therapy for metastatic solid tumor malignancies to the spine. Int J Radiat Oncol Biol Phys 97:64-74, 2017

22. Sahgal A, Atenafu EG, Chao S, Al-Omair A, Boehling N, Balagamwala EH, et al: Vertebral compression fracture after spine stereotactic body radiotherapy: a multi-institutional analysis with a focus on radiation dose and the spinal instability neoplastic score. J Clin Oncol 31:3426-3431, 2013

23. Sahgal A, Ma L, Weinberg V, Gibbs IC, Chao S, Chang UK, et al: Reirradiation human spinal cord tolerance for stereotactic body radiotherapy. Int J Radiat Oncol Biol Phys 82:107-116, 2012

24. Sahgal A, Weinberg V, Ma L, Chang E, Chao S, Muacevic A, et al: Probabilities of radiation myelopathy specific to stereotactic body radiation therapy to guide safe practice. Int $\mathbf{J}$ Radiat Oncol Biol Phys 85:341-347, 2013

25. Stubblefield MD, Ibanez K, Riedel ER, Barzilai O, Laufer I, Lis E, et al: Peripheral nervous system injury after high-dose single-fraction image-guided stereotactic radiosurgery for spine tumors. Neurosurg Focus 42(3):E12, 2017

26. Tang C, Hess K, Bishop AJ, Pan HY, Christensen EN, Yang JN, et al: Creation of a prognostic index for spine metastasis to stratify survival in patients treated with spinal stereotactic radiosurgery: secondary analysis of mature prospective trials. Int J Radiat Oncol Biol Phys 93:118-125, 2015

27. Tao R, Bishop AJ, Brownlee Z, Allen PK, Settle SH, Chang EL, et al: Stereotactic body radiation therapy for spinal metastases in the postoperative setting: a secondary analysis of mature phase 1-2 trials. Int J Radiat Oncol Biol Phys 95:1405-1413, 2016

28. Tokuhashi Y, Matsuzaki H, Oda H, Oshima M, Ryu J: A revised scoring system for preoperative evaluation of metastatic spine tumor prognosis. Spine (Phila Pa 1976) 30:2186-2191, 2005

\section{Disclosures}

The authors report no conflict of interest concerning the materials or methods used in this study or the findings specified in this paper.

\section{Author Contributions}

Conception and design: Ito. Acquisition of data: Ito, Ogawa. Analysis and interpretation of data: all authors. Drafting the article: Ito. Critically revising the article: Nihei, Shimizuguchi. Reviewed submitted version of manuscript: all authors. Study supervision: Nihei.

\section{Correspondence}

Kei Ito: Tokyo Metropolitan Cancer and Infectious Diseases Center Komagome Hospital, Tokyo, Japan. keiito@cick.jp. 